\title{
Covariance of metabolic and hemostatic risk indicators in men and women
}

\author{
H. Riese, ${ }^{1}$ T. G. M. Vrijkotte, ${ }^{1}$ P. Meijer, ${ }^{2}$ C. Kluft, ${ }^{2}$ E. J. C. De Geus ${ }^{1}$ \\ ${ }^{1}$ Vrije Universiteit, Amsterdam, The Netherlands \\ ${ }^{2}$ Gaubius Laboratory, TNO-PG, Leiden, The Netherlands
}

Summary Background and objective: Multivariate analyses on clusters of metabolic and hemostatic risk indicators implicitly assume good test-retest reliability of these variables, substantial covariance among the various indicators, stability of covariance structure over time, and comparable covariance structure in different subpopulations. The aim of the present study is to investigate these assumptions.

Methods: Repeated samples were taken of fasting insulin, triglycerides (TG), high-density cholesterol (HDL-C), lowdensity cholesterol (LDL-C), fibrinogen, tissue-type plasminogen activator (t-PA) antigen, t-PA activity, plasminogen activator inhibitor-1 (PAl-1) antigen to address their intra-week reliability and covariance structure. In the same workweek blood was drawn three times from 125 sedentary males (age $45.2 \pm 5.3$ years) and twice from 132 female nurses (age $33.7 \pm 8.0$ years).

Results: About half (44.8\%) of these women were oral contraceptives (OC) users. Only minor intra-week changes in absolute levels were found. Intra-week test-retest correlations varied between 0.52 (t-PA activity) and 0.94 (HDL-C) with an average value of 0.81 . In men, non-OC using women, and OC using women, the covariance matrices of the eight risk indicators were equal at day 1 and day 3 , testifying the good stability of covariance structure over time. Differences in covariance structure of all three groups were observed, which remained after correction for BMI and age. In men and non-OC-using women, significant correlation was found on all days between insulin and the other risk indicators with exception of fibrinogen and LDL-C. In OC users, insulin was correlated with TG, LDL-C, and fibrinogen.

Conclusion: The metabolic and hemostatic risk indicators showed good test-retest reliability, and their covariance is stable over time. Multivariate analyses of this cluster should be performed separately for men, non-OC-using women, and OC-using women. ( 2001 Harcourt Publishers Ltd

\section{INTRODUCTION}

Epidemiological research has shown that blood plasma levels of insulin, high-density cholesterol (HDL-C), lowdensity cholesterol (LDL-C), triglycerides (TG), fibrinogen and PAI-1 activity are risk indicators for cardio-vascular disease (CVD). ${ }^{1-7}$ Although these indicators are considered to represent independent disease processes (e.g. hypertension, atherosclerosis and thrombosis), current

Received: 14 August 2000

Accepted after revision: 22 December 2000

Correspondence to: $\mathrm{H}$. Riese, Vrije Universiteit, Department of Biological Psychology, Van der Boechorststraat 1, 1081 BT Amsterdam, The Netherlands. Tel.: + 3120 4448822; fax: + 3120 4448832; e-mail: h.riese@psy.vu.nl thinking emphasizes their clustering in particular individuals. In the insulin resistance syndrome (IRS), high insulin, LDL-C and TG levels and low HDL-C levels co-exist with an unfavourable fibrinolytic profile. ${ }^{8-12}$ Due to the additive and possibly synergistic effects of the underlying disease processes, small elevations of multiple metabolic and hemostatic risk indicators may signal a larger CVD disease risk than large deviations in one or few of these indicators. Consequently, recent studies on the effects of lifestyle, social economic class and chronic (work) stress have assessed clusters of hemostatic and metabolic risk indicators to compute the 'multivariate' CVD risk. ${ }^{13-16}$

Validity of a multivariate approach to CVD risk requires that: (1) the test-retest reliability over repeated 
measures of the various risk indicators is sufficiently high, (2) there is substantial covariance between the various risk indicators and (3) the structure of their covariance is reasonably stable over time and conditions. Although some information is available on the reliability and the covariance of metabolic and hemostatic risk of the IRS indicators ${ }^{17-19}$ an evaluation of the stability of their covariance structure is lacking entirely. Changes in covariance structure over time could easily emerge due to differential psychosocial, behavioural and infradian (weekly, monthly, seasonally) effects on each of these risk indicators. ${ }^{20-23}$ Such effects may compromise the stability of covariance structure, even if the bloodsampling procedures (time of day, dietary restrictions, venipuncture protocol, etc.) and blood analyses (on-site preparation, storage, biochemical assays, etc.) are optimally standardized.

Secondly, the extent to which the covariance structure of the risk indicators differs across (sub-) populations is uncharted. Such group differences in covariance structure could easily exist, for instance, in populations differing in factors known to be associated with the risk indicators like physical activity, experienced (work) stress, gender or oral contraceptive use. ${ }^{24-27}$ The latter two, gender and oral contraceptive effects, may selectively affect some of the risk indicators of the IRS, ${ }^{28,29}$ and possibly change their covariance to other indicators. Systematic group differences in the covariance of the metabolic and hemostatic risk indicators would imply that between subjects designs should take the differential covariance structure of the groups into account.

The present study repeatedly assessed levels of fasting insulin, LDL-C, HDL-C, TG, fibrinogen, t-PA antigen, t-PA activity and PAI-1 antigen within a single work week in three groups of subjects separately: men, non-oral contraceptive-(OC) using women and OC-using women. Test-retest reliability and covariance structure of the eight target risk indicators were computed for all three groups. Covariance of these multiple indicators is examined with structural equation modelling ${ }^{30}$ to test the stability of covariance structure across repeated measures within the groups, and to test for group differences in covariance structure.

\section{MATERIALS AND METHODS}

\section{Subjects}

In the present study, 125 male clerical workers from a large computer company (mean age $45.2 \pm 5.3$ years, range 35-55 years; BMI $25.1 \pm 2.8$ ) and 132 female nurses from three hospitals (mean age $33.7 \pm 8$ years, range $22-55$ years; BMI $23.9 \pm 4.0$ ) volunteered to participate. Subjects were selected from a larger sample to include only healthy non-pregnant subjects who were not receiving treatment or taking medication for hypertension, or known to suffer from cerebrovascular disease, hyperlipidaemia or diabetes mellitus. Also subjects who had used aspirin or other anti-inflammatory or analgesic medication were excluded from the final analyses. $29.6 \%$ of the men and $28.1 \%$ of the women were smokers, and $44.8 \%$ of the women were OC users. All subjects gave written informed consent before entrance to the study. Study and blood-sampling protocol were approved by the Ethics Committee of the Vrije Universiteit, Amsterdam.

\section{Procedure}

Because our blood variables are known to respond to a host of confounders (e.g. time of day, shift work, current or previous day meals, alcohol or coffee drinking and physical activity etc.) rigid standardization of blood sampling procedures was enforced to optimize test-retest reliability. Subjects were requested to fast and refrain from use of alcohol, coffee and tea after 23:00 the preceding night and to refrain from high-impact physical activity the preceding day. In both the male and the female population, blood was drawn at the workplace from the arm in a sitting position after at least $15 \mathrm{~min}$ rest. In the male population, blood was drawn on Monday, Wednesday and Friday, at the beginning of a workday, between 08:00 and 09:30. In the female population, blood was drawn solely at daytime shifts between 07:00 and 07:30. Female nurses had to work at least three successive daytime shifts, and the first measurement day had to be preceded by at least 2 non-working days (to make sampling comparable to the Monday measurement in the male population). The first blood sample was drawn at the first day of a daytime shift, and the second sample 2 days later, when the nurses were still on a daytime shift. After the first blood sample was drawn, subjects' body weight (to the nearest $100 \mathrm{~g}$ ) and height (to the nearest $\mathrm{cm}$ ) were measured in light clothing.

\section{Metabolic risk indicators}

Blood withdrawal was according to the Standardized European Concerted Action on Thrombosis (ECAT) assay procedures. ${ }^{31,32}$ Blood was drawn by venipuncture of the antecubital vein and sampled in six different vacutainers in the following order; serum with clot-activator $(5 \mathrm{ml})$, serum $(3 \mathrm{ml})$, Stabilyte ${ }^{\circledR}(5 \mathrm{ml}),{ }^{33}$ citrate $(5 \mathrm{ml})$, EDTA $(3 \mathrm{ml})$. All vacutainers were mixed by moving the vacutainers 5 times 'head over head' immediately after withdrawal. Fasting insulin (pmol/l) was determined with a immunoradiometric assay kit (Medgenix Diagnostics Fleurus, Belgium) ${ }^{34,35}$ from blood taken out of the 
serum-vacutainer. Blood had to clot for minimal $60 \mathrm{~min}$ at room temperature. Serum was separated by centrifugation at $2000 \times \mathrm{g}$ for $20 \mathrm{~min}$ at $4^{\circ} \mathrm{C}$. Aliquots of serum were stored at $-20^{\circ} \mathrm{C}$. Values were multiplied by 0.139 to convert fasting insulin into $\mathrm{mU} / \mathrm{l}$. For determination of TG and HDL-C the serum of the clot-activator vacutainer was used. Blood was allowed to clot for minimal $30 \mathrm{~min}$ and maximal $2 \mathrm{~h}$ at room temperature. Serum was separated by centrifugation at $2000 \times \mathrm{g}$ for $20 \mathrm{~min}$ at $4^{\circ} \mathrm{C}$. Lipid determinations were performed at the same day using the Vitros 250 Clinical Chemistry analyzer (Johnson \& Johnson, Rochester, USA) with Vitros clinical chemistry slides for TG. HDL-C was determined in serum after a precipitation step with HDL-C precipitant (Boehringer Mannheim, Mannheim, Germany). LDL-C was calculated according to the formula of Friedewald. ${ }^{36}$ All results are given in mmol/L. Stabilyte blood was drawn for the determination of t-PA activity. Citrated blood was withdrawn for determination of fibrinogen, t-PA antigen and PAI-1 antigen. Immediately after withdrawal, the vacutainers were put in melting ice and centrifuged within $60 \mathrm{~min}\left(2000 \times \mathrm{g}, 20 \mathrm{~min}\right.$ at $\left.4^{\circ} \mathrm{C}\right)$. Aliquots of plasma were snap-frozen immediately using solid carbon dioxide and stored at $-80^{\circ} \mathrm{C}$. t-PA activity was determined using the bio-functional immunosorbent assay Chromolize ${ }^{\mathrm{TM}} \mathrm{TPA}$ (Biopool, Umeå, Sweden). ${ }^{37}$ Results were expressed in IU/ml. Fibrinogen was determined using the STA coagulation analyzer (STAG-O, Asnières, France) and the STA Fibrinogen kit (Boehringer Mannheim, Germany). ${ }^{38}$ The results are expressed in $\mathrm{g} / \mathrm{L}$. t-PA antigen was measured using the enzyme immunoassay Imulyse ${ }^{\mathrm{TM}} \mathrm{tPA}$ (Biopool, Umeå, Sweden). ${ }^{39}$ PAI-1 antigen was measured using enzyme immunoassay Innotest PAI-1 (Innogenetics, Zwijndrecht, Belgium). ${ }^{40}$ Results for PAI- 1 antigen en t-PA antigen are expressed in $\mathrm{ng} / \mathrm{ml}$. The intra-assay and the inter-assay coefficient of variation, respectively were less then: 5.0 and $7.0 \%$ for fasting insulin, 3.5 and $5.0 \%$ for HDL-C, 3.0 and $5.0 \%$ for TG, 5.0 and $7.0 \%$ for fibrinogen, 10.0 and $12.0 \%$ for t-PA antigen, 7.5 and $10.0 \%$ for t-PA activity, and 10.0 and $10.0 \%$ for PAI- 1 antigen. For each of the blood variables all blood samples were analyzed in the same batch. Moreover, the blood samples, drawn from the same participant on repeated blood withdrawal occasions, were analyzed simultaneously on the same plate. No sample had been stored for more than 7 months.

For evaluation of hemoconcentration, hematocrit $(\mathrm{Ht})$, from EDTA blood was used. Immediately after withdrawal per participant 2 capillary tubes (Hawksley \& Sons Ltd., Sussex, England) were filled three-quarters with blood, sealed with SEAL-EASE ${ }^{\circledR}$ Tube Sealer (Becton Dickinson, Franklin Lakes, USA) and centrifuged for $6 \mathrm{~min}$ in a micro hematocrit centrifuge. A hematocritreader was used for determination the Ht values.

\section{Statistical analyses}

Analyses of intra-week effects and group differences were performed in a multivariate design using the General Linear Modeling (GLM in SPSS7.5 for Windows) procedure. The dependent variables in the GLM model were fasting insulin, HDL-C, LDL-C, TG, fibrinogen, t-PA antigen, t-PA activity and PAI-1 antigen. Men, non-OC-using women and OC-using women were entered in the model as between subject factor. Age and BMI were entered as covariates in the analyses. The GLM procedure was started with a model specification, which included all main effects and all second-, and third-order interactions. Subsequently, non-significant interactions were removed from the model specification and the GLM procedure was performed again. This step-down procedure ends when an exclusive significant interaction or a main effect is found. ${ }^{41}$ Test-retest reliability was assessed in three ways. First by computing Pearson correlation coefficients. Second by a method described in Fraser et $\mathrm{al}^{42}$ and Marckmann et al. ${ }^{20}$ using the assay variation in the duplicates and the variation across different measurement days, to obtain estimates of analytical variance $(\mathrm{Sa})$, average within-subject variance $(\mathrm{Si})$ and between subject variance (Sg). Analytical variance was extracted from the variance in the duplicates (as reflected in the intra-assay CV). Based on the criteria of Cotlove et al., ${ }^{43}$ which was repeated in Fraser et al. ${ }^{42}$ and adopted by the college of American Pathologists and the World association of societies of pathology, we specify the minimally acceptable CV for each of the assays (the $\mathrm{CV}$ of the assay should equal to or less than half of the normal intra-week biological variation also expressed as a CV). Third by calculating repeatability coefficients $\mathrm{RC}=2.77 \times\left(\sqrt{\mathrm{s}_{\mathrm{w}}}\right)$, after Bland, and Altman, ${ }^{44}$ using the within-subject's variances $\left(\mathrm{s}_{\mathrm{w}}\right)$ calculated according to the procedure described above.

The idea of a latent syndrome underlying various risk indicators can be easily reformulated in terms of a statistical technique called structural equation modelling (SEM). ${ }^{30}$ In SEM, a latent IRS factor can be postulated that has causal pathways to a number of latent factors reflecting the true score of the hemostatic and metabolic risk indicators. These latent factors are based, in turn, on repeated observations of each of the risk indicators (see Fig. 1).

The above approach of repeated measures of multiple risk indicators substantially increases the statistical power of both within subject (e.g. efficacy of medication) and between subject (e.g. case control comparison) designs. Structural equation modelling was performed using LISREL8. ${ }^{30}$ First we assessed the stability of the covariance matrices of the risk indicators within each group; this was only done for day 1 and day 3. A model is specified wherein the correlations between all risk 


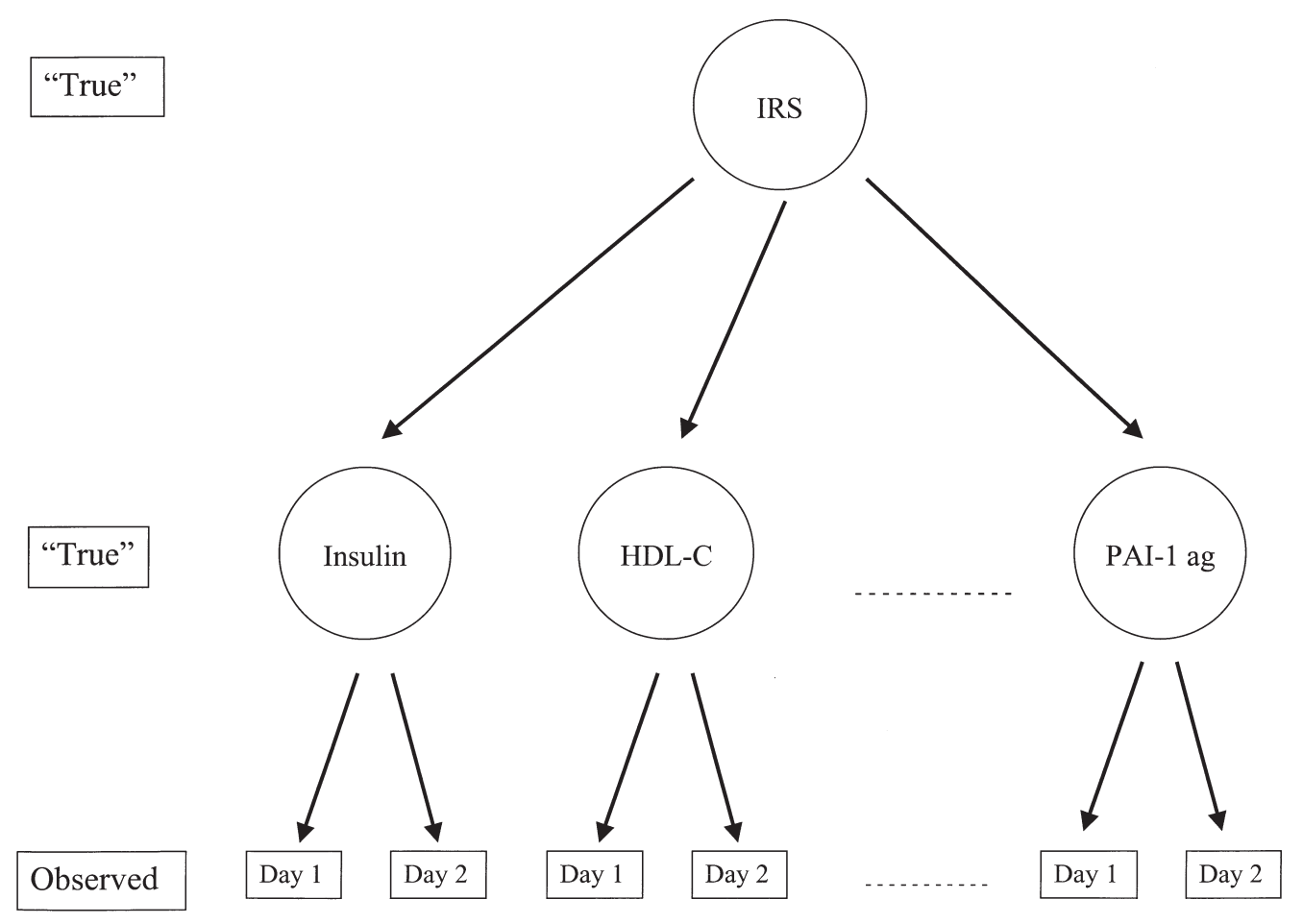

Fig. 1 Schematic representation of the influence of a latent IRS factor on the true score of various risk indicators. The true score of the risk indicators influences the observed measurements over repeated occasions.

indicators and their standard deviations are stated to be equal at both days. This model is fitted to the observed covariance in an iterative maximum likelihood procedure, yielding a chi-square parameter that indicates the goodness of fit of the model. Subsequently, a second model is specified wherein the correlations between all risk indicators are specified to be equal and their standard deviations are unequal. The difference in the chisquare goodness of fit parameters of these two models has itself a chi-square distribution. If the second more parsimonious model does not fit significantly worse than the first full model, the hypothesis that the covariance structure is equal on the 2 days is accepted. Secondly, in the same way comparisons of the covariance matrices between all combinations of the risk indicators were performed for the three groups. As a consequence of different statistical characteristics of the chi-square distribution, chi-square tests were carried out against a significance level of $P<0.01$.

\section{RESULTS}

All data were checked with regard to frequency distribution. Fasting insulin, TG, fibrinogen, t-PA antigen, t-PA activity and PAI-1 antigen were transformed to normal distribution by logarithmic transformation before entering in the statistical analysis. For readability, the backtransformed logarithmic mean and range of transformed risk indicators for the groups are given in Table 1.

\section{Intra week changes and group differences in absolute levels}

Values on the metabolic and hemostatic risk indicators and $\mathrm{Ht}$, obtained at day 1 and day 3 were tested for group differences across men, non-OC-using women and OC-using women. Age and BMI were included as covariates in this analysis. Two interactions involving group or day were found: group by $\operatorname{BMI}(\mathrm{F}(18,438)=2.5$, $P=0.001)$ and group by day $(\mathrm{F}(18,438)=2.3, P=0.002)$. Inspection of the univariate results showed the group by BMI interaction to be due to fasting insulin $(\mathrm{F}(2,226)=3.6, P=0.03)$, t-PA activity $(\mathrm{F}(2,226)=10.1$, $P<0.001)$, PAI-1 antigen $(\mathrm{F}(2,226)=6.2, P=0.003)$ and Ht $(\mathrm{F}(2,226)=4.4, P=0.01)$. Parameter estimates indicated that with increasing BMI, fasting insulin increased most in men and least in OC-using women. With increasing BMI, t-PA activity decreased most in men and least in OC-using women. With increasing BMI, PAI-1 antigen levels increased most in men and least in 


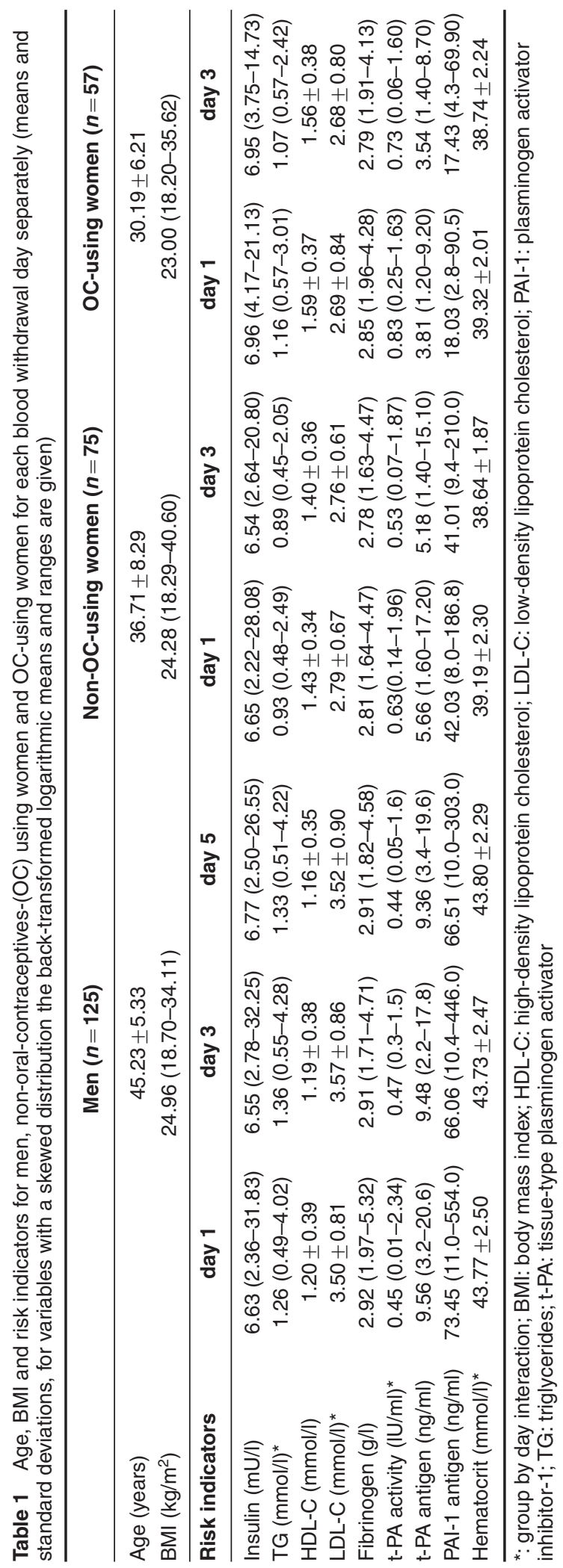


non-OC-using women. With increasing BMI, OC users had an increase in Ht level; men and non-OC users had a small decrease in Ht levels. The group by day interaction was due to TG $(\mathrm{F}(2,226)=4.9, P=0.008)$, LDL-C $(\mathrm{F}(2,226)=3.7, \quad P=0.03), \quad \mathrm{t}-\mathrm{PA}$ activity $(\mathrm{F}(2,226)=5.0$, $P=0.008)$ and $\mathrm{Ht}(\mathrm{F}(2,226)=3.8, P=0.02)$. These risk indicators increased from day 1 to day 3 in men and decreased in both groups of women. Ht did not change in men, but it did decrease in women from day 1 to day 3.

\section{Test-retest reliability}

Test-retest correlations between day 1 and day 3 in men and women, and correlations between day 3 and 5, and between day 1 and day 5 in men, varied between 0.52 (t-PA activity in women who used OCs) and 0.94 (LDL-C in men), with a medium value of 0.81 . All were highly significant $(P<0.001)$. In men, test-retest correlations were slightly lower for day $1-5$ compared to day $1-3$ as well as day $3-5$, except for t-PA antigen. Following Salomaa et al., ${ }^{44}$ we focused on the subjects that were in the highest quartile (lowest quartile for HDL-C and t-PA activity) of each risk indicator distribution on the first blood withdrawal occasion. The proportion of these subjects that were still in the highest quartile on a second withdrawal occasion was computed (for men separate proportions for day 1 and 3, and day 1 and 5 were computed). Table 2 shows these proportions. On average they were $70.1 \%$ (range 50.0-94.4\%). In men, the highest proportions were found for LDL-C and TG, and the lowest proportions were found for $\mathrm{Ht}$. Compared to OC users, in non-OC users, higher proportions were found for LDL-C, TG and insulin and lower proportions for HDL-C.

Following Fraser et $\mathrm{al}^{42}$ we computed the components of variance in each of the risk indicators due to between subject variance, within-subject variance (excluding analytical variance) and analytical variance (see Table 3 ). We additionally report the intra-assay coefficient of variation $(\mathrm{CV})$ that is minimally required to reliably detect intra-week within-subject variance $\left(\mathrm{CV}_{\text {analytical }} \leqslant 0.5 \times\right.$ $\mathrm{CV}_{\text {within-subject }}{ }^{41} \mathrm{HDL}-\mathrm{C}$, LDL-C, fibrinogen, and t-PA antigen did not meet this criterion in all three groups. Using the within-subject's variances $\left(\mathrm{s}_{\mathrm{w}}\right)$, repeatability coefficients (RC) after Bland and Altman ${ }^{44}$ were computed. In general, RCs appear to be higher in men than in women, particularly for insulin, TG, fibrinogen, t-PA antigen and PAI-1 antigen.

\section{Correlation structure of the risk indicators}

Table 4 displays the correlation structure of the risk indicators for both sexes. The metabolic and hemostatic risk indicators showed substantial intercorrelations in men (Table 4A) and women (Tables 4B \& 4C).

In men and non-OC-using women, significant correlation was found on all days between insulin and the other risk indicators with exception of fibrinogen and LDL-C. In OC users, insulin was systematically associated with TG, LDL-C, and fibrinogen only. Overall, the largest difference in correlation structure was found between men and OC-using women, with the non-OC-using women somewhere in between.

\section{Covariance structure of the risk indicators}

Differences in the covariance structure of the metabolic and fibrinolytic risk indicators of the first and second blood withdrawal day were tested using LISREL8. ${ }^{30}$ Results are shown in the upper panel of Table 5. Tests of the intra-week stability of the covariance structure were carried out for the three groups separately. In men and

Table 2 Proportion and number of men, non-oral-contraceptives-(OC) using women and OC-using women who were in the highest quartile (lowest quartile for HDL-C and t-PA-act) of the risk indicator distribution on the first blood withdrawal occasion also belonging to the highest quartile on the second blood withdrawal occasion

\begin{tabular}{|c|c|c|c|c|c|c|c|c|}
\hline \multirow[t]{3}{*}{ Risk indicators } & \multicolumn{4}{|c|}{ Men $(n=102)$} & \multirow{2}{*}{\multicolumn{2}{|c|}{$\begin{array}{c}\text { Non-OC-using women }(n=75) \\
\text { day } 1-3\end{array}$}} & \multirow{2}{*}{\multicolumn{2}{|c|}{$\begin{array}{l}\text { OC-using women }(n=57) \\
\text { day } 1-3\end{array}$}} \\
\hline & \multicolumn{2}{|c|}{ day $1-3$} & \multicolumn{2}{|c|}{ day 1-5 } & & & & \\
\hline & $\%$ & $(n)$ & $\%$ & $(n)$ & $\%$ & $(n)$ & $\%$ & $(n)$ \\
\hline Insulin (mU/l) & 73.1 & (19) & 68.0 & (17) & 83.3 & (15) & 61.5 & ( 8$)$ \\
\hline $\mathrm{TG}(\mathrm{mmol} / \mathrm{l})$ & 76.9 & (20) & 73.1 & (19) & 73.7 & (14) & 57.1 & ( 8) \\
\hline $\mathrm{HDL}-\mathrm{C}(\mathrm{mmol} / \mathrm{l})$ & 69.2 & (18) & 73.1 & (19) & 65.0 & (13) & 92.9 & (13) \\
\hline LDL-C (mmol/l) & 84.6 & (22) & 76.9 & (20) & 94.4 & (17) & 64.3 & (9) \\
\hline Fibrinogen $(\mathrm{g} / \mathrm{l})$ & 65.4 & (17) & 69.2 & (18) & 77.8 & (14) & 78.6 & (11) \\
\hline t-PA activity (IU/ml) & 65.4 & (17) & 70.4 & (19) & 57.9 & (11) & 50.0 & ( 7 ) \\
\hline t-PA antigen $(\mathrm{ng} / \mathrm{ml})$ & 69.2 & (18) & 73.1 & (19) & 75.0 & (15) & 78.6 & (11) \\
\hline PAl-1 antigen $(\mathrm{ng} / \mathrm{ml})$ & 76.9 & (20) & 61.5 & (16) & 63.2 & (12) & 57.1 & (8) \\
\hline Hematocrit $(\mathrm{mmol} / \mathrm{l})$ & 50.0 & (11) & 60.0 & (15) & 73.3 & (11) & 63.6 & $(7)$ \\
\hline
\end{tabular}

BMI: body mass index; HDL-C: high-density lipoprotein cholesterol; LDL-C: low-density lipoprotein cholesterol; PAI-1: plasminogen activator inhibitor-1; TG: triglycerides; t-PA: tissue-type plasminogen activator. 
both the non-OC-using and OC-using women the covariance matrices were equal for day 1 and day 3 $\left(\chi^{2}(8)=7.72, P=0.46 ; \chi^{2}(8)=10.72, P=0.22 ; \chi^{2}(8)=7.68\right.$, $P=0.47$ respectively).

The same procedure was performed in a multi-group LISREL8 analysis to test group differences. Comparisons between men and non-OC users, men and OC users and non-OC users and OC users were performed successively. Results are shown in the lower panel of Table 5. In this analysis the covariance matrices at day 1 and day 3 were specified to be equal within and between the groups. In addition, the standard deviations were equal within and between groups. These models all fitted poorly $\quad\left(\chi^{2}(192)=240.90, \quad P=0.0095 ; \quad \chi^{2}(192)=252.50\right.$, $P=0.002 ; \chi^{2}(192)=247.83, P=0.004$ respectively), so no further fitting of more parsimonious models were needed to conclude that the covariance structures between the groups differ. These results indicate that the covariance structure of the metabolic and hemostatic risk indicators, measured at 2 work days, were different in men, non-OC-using women and OC-using women.
This remained true after correction for differences in BMI and age in the three groups.

\section{DISCUSSION AND CONCLUSIONS}

Previous studies performing multivariate regression and multivariate ANOVA analyses on different clusters of metabolic and hemostatic risk indicators of the insulin resistance syndrome have tacitly assumed that: (1) the univariate test-retest reliability over repeated measures of the various indicators is good to excellent, (2) there is substantial covariance between these risk indicators, and (3) the structure of their covariance is stable over time. This study directly tested these assumptions and found them to be essentially correct. With regard to test-retest reliability, 42.9 to $92.9 \%$ of the observed variance in the risk indicators could be attributed to between subject variance with an average value of $81 \%$. Moreover, the proportion of subjects that were in the extreme quartile of the risk indicator distribution on two successive

Table 3 Estimates of between subject (BS), within subject (WS) and analytical (A) variation (percentages in brackets), and coefficients of variation $(\mathrm{CV})$ of the risk indicators for men $\left(n_{\text {ind }}=102, n_{\text {obs }}=612\right)$, non-oral-contraceptives- $(O C)$ using women $\left(n_{\text {ind }}=75, n_{\text {obs }}=300\right)$ and OC-using women $\left(n_{\text {ind }}=57, n_{\text {obs }}=228\right)$, separately. Repeatability coefficients $(R C)$ for the three groups separately are given as well

\begin{tabular}{|c|c|c|c|c|c|c|c|c|c|c|c|}
\hline & \multicolumn{3}{|c|}{ Between subject } & \multicolumn{3}{|c|}{ Within subject } & \multicolumn{3}{|c|}{ Analytical } & \multirow[b]{2}{*}{$1 / 2 C V_{\text {ws }}$} & \multirow[b]{2}{*}{ RC } \\
\hline & Variance & (\%) & $\mathrm{CV}_{\mathrm{BS}}$ & Variance & (\%) & $\mathrm{CV}_{\mathrm{ws}}$ & Variance & (\%) & $\mathrm{Cv}_{\mathrm{A}}$ & & \\
\hline \multicolumn{12}{|l|}{ Men } \\
\hline insulin & 16.71 & $(79.5)$ & 53.9 & 4.16 & (19.8) & 26.9 & 0.14 & $(0.7)$ & 5.0 & 13.5 & 5.65 \\
\hline TG & 0.41 & $(68.0)$ & 43.4 & 0.19 & $(31.7)$ & 29.5 & 0.0020 & $(0.3)$ & 3.0 & 14.8 & 1.21 \\
\hline HDL-C & 0.13 & (90.9) & 29.9 & 0.011 & $(7.9)$ & 8.9 & 0.0017 & $(1.2)$ & 3.5 & 4.5 & 0.29 \\
\hline LDL-C & 0.70 & (91.2) & 23.5 & 0.052 & $(6.8)$ & 6.5 & 0.015 & $(2.0)$ & 3.5 & 3.3 & 0.63 \\
\hline fibrinogen & 0.25 & (81.6) & 16.9 & 0.035 & (11.3) & 6.3 & 0.022 & $(7.1)$ & 5.0 & 3.2 & 0.52 \\
\hline t-PA activity & 0.072 & $(60.2)$ & 48.3 & 0.046 & (38.3) & 37.7 & 0.0018 & (1.5) & 7.5 & 18.9 & 0.59 \\
\hline t-PA antigen & 9.074 & $(74.8)$ & 29.8 & 2.028 & (16.7) & 14.1 & 1.026 & $(8.5)$ & 10.0 & 7.1 & 3.95 \\
\hline PAl-1 antigen & 3935.52 & (76.1) & 70.0 & 1152.76 & (22.3) & 37.9 & 80.69 & $(1.6)$ & 10.0 & 19.0 & 94.05 \\
\hline \multicolumn{12}{|c|}{ Non-OC-using women } \\
\hline insulin & 10.00 & (83.5) & 43.9 & 1.85 & (15.4) & 18.9 & 0.13 & $(1.1)$ & 5.0 & 9.5 & 3.77 \\
\hline $\mathrm{TG}$ & 0.095 & $(68.0)$ & 31.3 & 0.044 & (31.4) & 21.7 & 0.00084 & $(0.6)$ & 3.0 & 10.9 & 0.58 \\
\hline HDL-C & 0.11 & (88.1) & 23.2 & 0.013 & (10.0) & 8.1 & 0.0024 & (1.9) & 3.5 & 4.1 & 0.32 \\
\hline LDL-C & 0.36 & (84.6) & 21.8 & 0.032 & $(8.0)$ & 6.5 & 0.0094 & (2.4) & 3.5 & 3.3 & 0.50 \\
\hline fibrinogen & 0.26 & $(90.0)$ & 17.8 & 0.0090 & $(3.1)$ & 3.3 & 0.020 & $(6.9)$ & 5.0 & 1.7 & 0.26 \\
\hline t-PA activity & 0.076 & (62.9) & 42.1 & 0.042 & (35.0) & 31.3 & 0.0025 & $(2.1)$ & 7.5 & 15.7 & 0.57 \\
\hline t-PA antigen & 4.30 & $(82.4)$ & 35.4 & 0.58 & (11.1) & 13.0 & 0.34 & $(6.5)$ & 10.0 & 6.5 & 2.11 \\
\hline PAI-1 antigen & 954.20 & $(68.6)$ & 60.9 & 412.06 & (29.6) & 40.0 & 25.66 & $(1.8)$ & 10.0 & 20.0 & 56.23 \\
\hline \multicolumn{12}{|l|}{ OC-using women } \\
\hline insulin & 4.91 & (64.3) & 30.2 & 2.59 & (33.9) & 22.0 & 0.14 & $(1.8)$ & 5.0 & 11.0 & 4.46 \\
\hline $\mathrm{TG}$ & 0.16 & (75.6) & 33.5 & 0.050 & (23.8) & 18.8 & 0.0013 & $(0.6)$ & 3.0 & 9.4 & 0.62 \\
\hline HDL-C & 0.13 & (92.9) & 23.0 & 0.0070 & $(5.0)$ & 5.4 & 0.0030 & $(2.1)$ & 3.5 & 2.7 & 0.23 \\
\hline LDL-C & 0.64 & (92.8) & 29.8 & 0.041 & $(5.9)$ & 7.6 & 0.0088 & (1.3) & 3.5 & 3.8 & 0.56 \\
\hline fibrinogen & 0.29 & $(87.8)$ & 18.9 & 0.019 & $(5.8)$ & 4.9 & 0.021 & $(6.4)$ & 5.0 & 2.5 & 0.38 \\
\hline t-PA activity & 0.039 & (42.8) & 23.6 & 0.048 & (52.8) & 26.1 & 0.0040 & $(4.4)$ & 7.5 & 13.1 & 0.61 \\
\hline t-PA antigen & 2.56 & (82.1) & 40.0 & 0.40 & (12.8) & 15.7 & 0.16 & (5.1) & 10.0 & 7.9 & 1.75 \\
\hline $\mathrm{PAI}-1$ antigen & 187.52 & $(85.7)$ & 63.5 & 124.74 & (13.7) & 51.8 & 4.76 & $(0.6)$ & 10.1 & 23.5 & 30.94 \\
\hline
\end{tabular}

BMI: body mass index; HDL-C: high-density lipoprotein cholesterol; LDL-C: low-density lipoprotein cholesterol; $n_{\text {ind }}$ : number of individuals; $\mathrm{n}_{\mathrm{obs}}$ : number of observations; PAl-1: plasminogen activator inhibitor-1; TG: triglycerides; t-PA: tissue-type plasminogen activator. 
Table 4A Correlation structure of the risk indicators in men

\begin{tabular}{|c|c|c|c|c|c|c|c|c|}
\hline & Insulin & TG & HDL-C & LDL-C & Fibrinogen & t-PA act & t-PA ag & PAl-1 ag \\
\hline \multicolumn{9}{|l|}{ Day 1} \\
\hline insulin & - & & & & & & & \\
\hline TG & $0.34 \dagger$ & - & & & & & & \\
\hline HDL-C & $-0.41 \dagger$ & $-0.39 \dagger$ & - & & & & & \\
\hline LDL-C & & $0.37 \dagger$ & & - & & & & \\
\hline Fibrinogen & & & & $0.30 \dagger$ & - & & & \\
\hline t-PA activity & $-0.35 \dagger$ & $-0.23^{*}$ & $0.35 †$ & & & - & & \\
\hline t-PA antigen & $0.39 \dagger$ & $0.39 \dagger$ & $-0.43 \dagger$ & $0.26^{*}$ & & $-0.25 \dagger$ & - & \\
\hline PAl-1 antigen & $0.40 \dagger$ & $0.42 \dagger$ & $-0.43 \dagger$ & $0.21^{*}$ & & $-0.76 \dagger$ & $0.64 \dagger$ & - \\
\hline $\mathrm{BMI}$ & $0.41 \dagger$ & $0.27 \dagger$ & $-0.36 \dagger$ & & & $-0.54 \dagger$ & $0.44 \dagger$ & $0.60 \dagger$ \\
\hline \multicolumn{9}{|l|}{ Day 3} \\
\hline insulin & - & & & & & & & \\
\hline TG & $0.27 \dagger$ & - & & & & & & \\
\hline HDL-C & $-0.37 \dagger$ & $-0.43+$ & - & & & & & \\
\hline LDL-C & & $0.27 \dagger$ & & - & & & & \\
\hline fibrinogen & & & & $0.28 \dagger$ & - & & & \\
\hline t-PA activity & $-0.54 \dagger$ & $-0.41 \dagger$ & $0.32 \dagger$ & & & - & & \\
\hline t-PA antigen & $0.43 \dagger$ & $0.39 \dagger$ & $-0.34 \dagger$ & & & $-0.44 \dagger$ & - & \\
\hline PAl-1 antigen & $0.56 \dagger$ & $0.49 \dagger$ & $-0.28 \dagger$ & & & $-0.78 \dagger$ & $0.70 \dagger$ & - \\
\hline $\mathrm{BMI}$ & $0.54 \dagger$ & $0.36 \dagger$ & $-0.39 \dagger$ & & & $-0.61 \dagger$ & $0.44 \dagger$ & $0.61 \dagger$ \\
\hline \multicolumn{9}{|l|}{ Day 5} \\
\hline insulin & - & & & & & & & \\
\hline TG & $0.35 \dagger$ & - & & & & & & \\
\hline HDL-C & $-0.38 \dagger$ & $-0.36 \dagger$ & - & & & & & \\
\hline LDL-C & & $0.26 \dagger$ & & - & & & & \\
\hline fibrinogen & & & & $0.21^{*}$ & - & & & \\
\hline t-PA activity & $-0.57 \dagger$ & $-0.40 \dagger$ & $0.28 \dagger$ & & & - & & \\
\hline t-PA antigen & $0.45 \dagger$ & $0.38 \dagger$ & $-0.39 \dagger$ & & & $-0.43 \dagger$ & - & \\
\hline PAl-1 antigen & $0.56 \dagger$ & $0.47 \dagger$ & $-0.32 \dagger$ & & & $-0.79 \dagger$ & $0.76 \dagger$ & - \\
\hline $\mathrm{BMI}$ & $0.59 \dagger$ & $0.33 \dagger$ & $-0.37 \dagger$ & & & $-0.51 \dagger$ & $0.40 \dagger$ & $0.52 \dagger$ \\
\hline
\end{tabular}

BMI: body mass index; HDL-C: high-density lipoprotein cholesterol; LDL-C: low-density lipoprotein cholesterol; PAI-1: plasminogen activator inhibitor-1; TG: triglycerides; t-PA: tissue-type plasminogen activator. Non-significant correlations are omitted: ${ }^{*}: P<0.05 ; \dagger: P<0.01$.

Table 4B Correlation structure of the risk indicators in non-oral contraceptives using women

\begin{tabular}{|c|c|c|c|c|c|c|c|c|}
\hline & Insulin & TG & HDL-C & LDL-C & Fibrinogen & t-PA act & t-PA ag & PAl-1 ag \\
\hline \multicolumn{9}{|l|}{ Day 1} \\
\hline insulin & - & & & & & & & \\
\hline TG & & - & & & & & & \\
\hline HDL-C & $-0.34 \dagger$ & $-0.41 \dagger$ & - & & & & & \\
\hline LDL-C & & $0.34 \dagger$ & & - & & & & \\
\hline fibrinogen & $0.27^{\star}$ & & & $0.28^{*}$ & - & & & \\
\hline t-PA activity & $-0.24^{\star}$ & & & $-0.24^{*}$ & $-0.29^{*}$ & - & & \\
\hline t-PA antigen & $0.32 \dagger$ & $0.50 \dagger$ & $-0.29^{*}$ & & $0.28^{*}$ & $-0.36 t$ & - & \\
\hline PAl-1 antigen & $0.38 \dagger$ & $0.37 \dagger$ & $-0.31 \dagger$ & $0.25^{*}$ & $0.30 \dagger$ & $-0.75 t$ & $0.67 \dagger$ & - \\
\hline BMI & $0.54 \dagger$ & $0.26^{\star}$ & $-0.25^{\star}$ & & $0.45 \dagger$ & $-0.47 \dagger$ & $0.42 \dagger$ & $0.51 \dagger$ \\
\hline \multicolumn{9}{|l|}{ Day 3} \\
\hline insulin & - & & & & & & & \\
\hline $\mathrm{TG}$ & $0.27^{*}$ & - & & & & & & \\
\hline HDL-C & $-0.27^{\star}$ & $-0.31 \dagger$ & - & & & & & \\
\hline LDL-C & & $0.33 \dagger$ & & - & & & & \\
\hline fibrinogen & $0.32 \dagger$ & & & $0.25^{\star}$ & - & & & \\
\hline t-PA activity & $-0.32^{\star}$ & $-0.26^{*}$ & $0.42 \dagger$ & & $-0.35 \dagger$ & - & & \\
\hline t-PA antigen & $0.34 \dagger$ & $0.47 \dagger$ & $-0.27^{\star}$ & $0.23^{*}$ & $0.28^{*}$ & $-0.43 \dagger$ & - & \\
\hline PAI-1 antigen & $0.38 \dagger$ & $0.37 \dagger$ & $-0.37 \dagger$ & $0.23^{*}$ & $0.32 \dagger$ & $-0.84 \dagger$ & $0.70 \dagger$ & - \\
\hline BMI & $0.40 \dagger$ & & $-0.28^{*}$ & $0.24^{*}$ & $0.48 \dagger$ & $-0.57 \dagger$ & $0.37 \dagger$ & $0.52 \dagger$ \\
\hline
\end{tabular}

BMI: body mass index; HDL-C: high density lipoprotein cholesterol; LDL-C: low density lipoprotein cholesterol; PAI-1: plasminogen activator inhibitor-1; TG: triglycerides; t-PA: tissue-type plasminogen activator. Non-significant correlations are omitted: *: $P<0.05 ; \uparrow: P<0.01$. 
Table 4C Correlation structure of the risk indicators in oral contraceptives using women

\begin{tabular}{|c|c|c|c|c|c|c|c|c|}
\hline & Insulin & TG & HDL-C & LDL-C & Fibrinogen & t-PA act & t-PA ag & PAl-1 ag \\
\hline \multicolumn{9}{|l|}{ Day 1} \\
\hline insulin & - & & & & & & & \\
\hline TG & $0.41 \dagger$ & - & & & & & & \\
\hline HDL-C & & & - & & & & & \\
\hline LDL-C & $0.39 \dagger$ & $0.30^{*}$ & & - & & & & \\
\hline fibrinogen & $0.30^{*}$ & & & & - & & & \\
\hline t-PA activity & & & & & & - & & \\
\hline t-PA antigen & & & & & & & - & \\
\hline PAI- 1 antigen & & & & & & $-0.59 \dagger$ & $0.65 \dagger$ & - \\
\hline BMI & $0.39 \dagger$ & & & & $0.47 \dagger$ & & & $0.37 \dagger$ \\
\hline \multicolumn{9}{|l|}{ Day 3} \\
\hline insulin & - & & & & & & & \\
\hline TG & $0.38 †$ & - & & & & & & \\
\hline HDL-C & & & - & & & & & \\
\hline LDL-C & $0.32^{*}$ & $0.35 †$ & $-0.34^{\star}$ & - & & & & \\
\hline fibrinogen & $0.27^{*}$ & $0.34 \dagger$ & & & - & & & \\
\hline t-PA activity & $-0.32^{*}$ & & & $-0.38 \dagger$ & & - & & \\
\hline $\begin{array}{l}\text { t-PA antigen } \\
\text { PAl-1 antigen }\end{array}$ & & & & & & & $\overline{-}$ & \\
\hline $\begin{array}{l}\text { PAI-1 antigen } \\
\text { BMI }\end{array}$ & $0.33^{\star}$ & & & & & $-0.61 \dagger$ & $0.64 \dagger$ & - \\
\hline BMI & $0.39 \dagger$ & & & & $0.49 \dagger$ & $-0.28^{*}$ & $0.30^{*}$ & $0.41 \dagger$ \\
\hline
\end{tabular}

BMI: body mass index; HDL-C: high-density lipoprotein cholesterol; LDL-C: low-density lipoprotein cholesterol; PAI-1: plasminogen activator inhibitor-1; TG: triglycerides; t-PA: tissue-type plasminogen activator. Non-significant correlations are omitted: *: $P<0.05 ; \dagger: P<0.01)$.

Table 5 Upper panel: tests for equality of covariance matrices of the metabolic and hemostatic risk indicators on day 1 and 3 for men $(n=104)$, non-oral contraceptives using women $(n=75)$ and oral contraceptives using women ( $n=57$; a non-significant $\Delta \chi^{2}$-value means that the covariance structures were equal for day 1 and day 3 ). Lower panels: tests for equality of covariance matrices between the three groups (a significant $\chi^{2}$-value means that the covariance structures were different between the groups)

\begin{tabular}{|c|c|c|c|c|c|c|}
\hline Model specification & df & $\chi^{2}$ & $P$-value & $\Delta \mathrm{df}$ & $\Delta \chi^{2}$ & $P$-value \\
\hline \multicolumn{7}{|l|}{ Day differences } \\
\hline $\begin{array}{l}\text { Men } \\
\begin{array}{l}\text { 1. } R_{1 \mathrm{~m}}=R_{3 \mathrm{~m}},{s d_{1 \mathrm{~m}}} \neq s d_{3 \mathrm{~m}} \\
\text { 2. } R_{1 \mathrm{~m}}=R_{3 \mathrm{~m}}, \mathrm{sd}_{1 \mathrm{~m}}=s d_{3 \mathrm{~m}} \\
\text { Model } 1 \text { vs. model } 2\end{array}\end{array}$ & $\begin{array}{l}56 \\
64\end{array}$ & $\begin{array}{l}75.75 \\
83.47\end{array}$ & $\begin{array}{l}0.04 \\
0.05\end{array}$ & 8 & 7.72 & 0.46 \\
\hline $\begin{array}{l}\text { Non-OC-using women } \\
\text { 3. } R_{1 \text { nooc }}=R_{3 \text { nooc, }}, s d_{1 \text { nooc }} \neq s d_{3 \text { nooc }} \\
\text { 4. } R_{1 \text { nooc }}=R_{3 \text { nooc, }}, d_{1 \text { nooc }}=s d_{3 \text { nooc }} \\
\text { Model } 3 \text { vs. model } 4\end{array}$ & $\begin{array}{l}56 \\
64\end{array}$ & $\begin{array}{l}54.83 \\
65.55\end{array}$ & $\begin{array}{l}0.52 \\
0.42\end{array}$ & 8 & 10.72 & 0.22 \\
\hline $\begin{array}{l}\text { OC-using women } \\
\text { 5. } \mathrm{R}_{1 \mathrm{oc}}=\mathrm{R}_{3 \mathrm{oc},}, \mathrm{sd}_{1 \mathrm{oc}} \neq \mathrm{sd}_{3 \mathrm{oc}} \\
\text { 6. } \mathrm{R}_{1 \mathrm{oc}}=\mathrm{R}_{3 \mathrm{oc}}, \mathrm{sd}_{1 \mathrm{oc}}=\mathrm{sd}_{30 \mathrm{c}} \\
\text { Model } 5 \text { vs. model } 6\end{array}$ & $\begin{array}{l}56 \\
64\end{array}$ & $\begin{array}{l}63.14 \\
70.82\end{array}$ & $\begin{array}{l}0.24 \\
0.26\end{array}$ & 8 & 7.68 & 0.47 \\
\hline \multicolumn{7}{|l|}{ Group differences } \\
\hline $\begin{array}{l}\text { Men vs. non-OC using women } \\
\quad \text { 7. } R_{1 \mathrm{~m}}=\mathrm{R}_{3 \mathrm{~m}}=\mathrm{R}_{1 \text { nooc }}=\mathrm{R}_{3 \mathrm{nooc}}, \mathrm{sd}_{1 \mathrm{~m}}=\mathrm{sd}_{3 \mathrm{~m}}=s d_{1 \text { nooc }}=\mathrm{sd}_{3 \text { nooc }}\end{array}$ & 192 & 240.90 & 0.0095 & & & \\
\hline $\begin{array}{l}\text { Men vs. OC-using women } \\
\text { 8. } R_{1 \mathrm{~m}}=R_{3 \mathrm{~m}}=R_{1 \mathrm{oc}}=R_{3 \mathrm{oc}}, s d_{1 \mathrm{~m}}=s d_{3 \mathrm{~m}}=s d_{1 \mathrm{oc}}=s d_{3 o c}\end{array}$ & 192 & 252.50 & 0.002 & & & \\
\hline $\begin{array}{l}\text { OC-using women vs. non-OC using women } \\
\text { 9. } R_{10 c}=R_{3 o c}=R_{1 \text { nooc }}=R_{3 \text { nooc }}, s d_{10 c}=s d_{30 c}=s d_{1 \text { nooc }}=s d_{3 \text { nooc }}\end{array}$ & 192 & 247.83 & 0.004 & & & \\
\hline
\end{tabular}

R: correlation matrix; sd: standard deviation; 1 : day 1; 3: day 3; m: men; nooc: women who do not use oral contraceptives; OC: women who use oral contraceptives; df: degrees of freedom; $\Delta$ : delta.

withdrawal days was high (70\% on average). Other studies have reported comparably short-term reliability coefficients for insulin, ${ }^{17}$ lipoproteins ${ }^{46}$ fibrinogen, ${ }^{47}$ t-PA antigen ${ }^{48}$ and PAI- 1 antigen ${ }^{48,49}$ in both male and female populations. This study is the first to additionally test for possible changes in the covariance structure of metabolic 
and hemostatic risk indicators across repeated measures. The results show that, at least across a single workweek, the covariance structure between hemostatic and metabolic risk indicators are stable. Taken together, these results suggest that in epidemiological studies blood samples drawn on different days of the week will yield similar results. The huge logistical impact on a study design of having to measure all subjects on exactly the same day of the week is not justified by our results.

In our study: (1) the samples of all subjects were frozen and saved to be analyzed in a single batch, (2) measurement conditions (time of day, shift, protocol for blood handling, transport and storage, etc.) were highly standardized, and (3) experimental protocol minimized confounding factors (diet, smoking, alcohol use, recent exercise etc.). With Fraser et al., ${ }^{42}$ we believe that these conditions should be met in future studies as much as possible. Under these optimal conditions, Fraser et $\mathrm{al}^{42}$ specified the minimally acceptable $\mathrm{CV}$ of biochemical assays to be equal to or less than half of the average within-subject variation also expressed as a CV. Because of high test-retest reliability, our assays for HDL-C, LDL-C, fibrinogen, and t-PA antigen were not adequate to detect intra-week within-subject variance in all or some of the groups according to this criterion. However, within subject variation in these risk indicators probably increases when measurements are spaced over longer periods of time, due to additional monthly cycles and seasonal effects, although previous studies suggest that such seasonal variation is small in comparison to short-term variation. ${ }^{19}$ More importantly, intra-week within subject variation is likely to be higher in patient populations than in the present healthy subjects, because higher mean levels usually coincide with higher variances. Therefore, minimally acceptable $\mathrm{CV}$ of the assays in single patient studies in clinical settings is probably larger than reported in Table 3A. A relatively large intra-week within-subject variance was found for TG, t-PA activity and PAI- 1 antigen. This means that a single measurement of these risk indicators will be a poor indicator of the 'true' score. In population-based studies, trueness of measurement is usually increased by measuring a variable in more subjects or by assessing the variable a repeated number of times. The former is costly, and the latter is most effective if the correlation between repeated measures is high. The present study demonstrated the validity of a third strategy. Measurement of multiple indicators that are highly correlated can be as informative about the value of a single indicator as many repeated measurements of that single variable. Based on our results, measurement of t-PA activity and t-PA antigen in men (average correlations to PAI- 1 antigen is -0.79 and 0.71 respectively) is almost as informative about PAI-1 as measuring PAI-1 three times (average test-retest is 0.80). Logistically, it is much easier to measure three parameters on 2 days, than a single parameter on six different days. More importantly, in the case of the risk indicators of the insulin-resistance syndrome, a multivariate approach is theoretically by far the most attractive. Studies assessing epidemiological risk, and ultimately even clinical studies, want to assess the subject's latent CVD risk. Because of their possible synergistic effects, a combination of high levels of all risk indicators may be more informative about the subjects CVD risk, than a high level in a single indicator. Therefore, a design with a few repeated measures of these multiple correlated risk indicators is an optimal way to assess the multivariate CVD risk conveyed by the insulin resistance syndrome. It has good statistical power, it is easier to implement (measurements on 2 or 3 days within a single week rather than repeated measurements across many weeks) and is theoretically meaningful. Because clear group differences were shown in covariance structure for men, non-OC-using women and OC-using women results of such analyses should be performed separately within each group. In general, when comparing different groups, multivariate analyses of mean, variance and covariance of the risk indicators is to be preferred above conventional analyses testing for mean and variance alone.

In conclusion, two measurements within the same week of these multiple correlated metabolic and hemostatic risk indicators showed them to have good testretest reliability, and a stable covariance structure over time. However, the covariance structure is different for men, non-OC-using women, and OC-using women. Future multivariate model fitting on this metabolic and hemostatic risk cluster should estimate the parameters separately for these three groups.

\section{ACKNOWLEDGEMENTS}

Dr C. Dolan and Dr D. L. Knol are thanked for their help and advise on the statistical analyses. This work was supported by grants from the Netherlands Heart Foundation (NHS grant 94.030) and the Netherlands Organization for Scientific Research (NWO grant 904-64-045).

\section{REFERENCES}

1. Després JP, LaMarche $B$, Mauriège $P$ et al. Hyperinsulinemia as an independent risk factor for ischemic heart disease. $\mathrm{N}$ Engl J Med 1996; 334: 952-957.

2. Ernst E, Resch KL. Fibrinogen as a cardiovascular risk factor: a meta-analysis and review of the literature. Ann Intern Med 1993; 118: 956-963.

3. Wu KK, Folsom AR, Heis G, Davis CE, Colan MG, Barnes R. Association of coagulation factors and inhibitors with carotid artery atherosclerosis. Early results of the Atherosclerosis Risk in Communities (ARIC) Study. Ann Epidemiol 1992; 2: 471-480. 
4. Dawson S, Henney A. The status of PAI-1 as risk factor for arterial and thrombotic disease: a review. Atherosclerosis 1992; 95: 105-117.

5. Austin MA. Plasma triglyceride and coronary heart disease. Arterioscler Thromb 1991; 11: 2-14.

6. Gordon DJ, Probsfield JL, Garrison RJ et al. High-density lipoprotein cholesterol and cardiovascular disease: four prospective American studies. Circulation 1989; 79: 9-15.

7. Lindahl B, Asplund K, Eliasson M, Evrin P-E. Insulin resistance syndrome and fibrinolytic activity: the Northern Sweden MONICA Study. Intern J Epidemiol 1996; 25: 291-299.

8. Vague P, Raccah D, Scelles V. Hypofibrinolysis and the insulin resistance syndrome. Int J Obes Relat Metab Disord 1995; 19: S11-15.

9. Reaven GM. Syndrome X: 6 years later. J Intern Med 1994; 236: $13-22$.

10. Asplund-Carlson A, Hamsten A, Wiman B, Carlson, LA. Relationship between plasma plasminogen activator inhibitor-1 activity and VLDL triglyceride concentration, insulin levels and insulin sensitivity: studies in randomly selected normo- and hypertriglyceridaemic men. Diabetologia 1993; 36: 817-825.

11. Daae LN, Kierulf $P$, Landaas $S$, Urdal P. Cardiovascular risk factors: interactive effects of lipids, coagulation and fibrinolysis. Scand J Clin Lab Invest 1993; 53: 19-27.

12. Fontbonne AM, Eschwege EM. Insulin and cardiovascular disease. Paris Prospective Study. Diabetes Care 1991; 14: 461-469.

13. Schnall PL, Landsbergis PA, Baker D. Job strain and cardiovascular disease. Annu Rev Public Health 1994; 15: 381-411.

14. Markowe HLJ, Marmot MG, Shipley MJ et al. Fibrinogen: a possible link between social class and coronary heart disease. Br Med J 1985; 291: 1312-1314.

15. Siegrist J, Peter R, Cremer P, Seidel D. Chronic workstress is associated with atherogenic lipids and elevated fibrinogen in middle-aged men. J Int Med 1997; 242: 149-156.

16. Ishizaki M, Tsuritani I, Noboriska Y, Yamada Y, Tabata M, Nakagawa H. Relationship between job stress and plasma fibrinolytic activity in male Japanese workers. Int Arch Occup Environ Health 1996; 68: 315-320.

17. Mooy JM, Grootenhuis PA, De Vries H et al. Intra-individual variation of glucose, specific insulin and proinsulin concentrations measured by two oral glucose tolerance tests in a general Caucasian population: the Hoorn Study. Diabetologia 1996; 39: 298-305.

18. De Maat MPM, De Bart ACW, Hennis BC et al. Interindividual and intraindividual variability in plasma fibrinogen, TPA antigen, PAI activity, and CRP in healthy, young volunteers and patients with angina pectoris. Arterioscler Thromb Vasc Biol 1996; 16: 1156-1162.

19. Markman P, Sandstrøm B, Jespersen J. The variability of and the association between measures of blood coagulation, fibrinolysis and blood lipids. Atheroscler 1992; 96: 235-244.

20. Tunstall-Pedoe H, Woodward M, Tavendale R, Brook RA, McCluskey MK. General Practice: Comparison of the prediction by 27 different factors of coronary heart disease and death in men and women of the Scottish heart health study: cohort study. Br Med J 1997; 315: 722-729.

21. Räikkönen K, Keltikangas-Jarvinen L, Adlercreutz H, Hautanen A Psychosocial stress and the insulin resistance syndrome. Metabolism 1996; 45: 1533-1538.

22. Weidner G, Boughal T, Connor SL, Pieper C, Mendell NR. Relationship of job strain to standard coronary risk factors and psychological characteristics in women and men of the Family Heart Study. Health Psychol 1997; 16: 239-247.

23. Juhan-Vague I, Alessi MC, Raccah D et al. Daytime fluctuations of plasminogen activator inhibitor 1 (PAI-1) in populations with high PAI-1 levels. Thromb Haemost 1992; 67: 76-82.

24. De Geus EJC, Kluft C, De Bart ACW, Van Doornen LJP. Effects of exercise training on plasminogen activator inhibitor activity. Med Sci Sports Exerc 1992; 24: 1210-1219.

25. Brindley DN, McCann BS, Niaura R, Stoney CM, Suarez EC. Stress and lipoprotein metabolism: modulators and mechanisms. Metabolism 1993; 42: 3-15.

26. Niaura R, Stoney CM, Herbert PN. Lipids in psychological research: the last decade. Biol Psychol 1992; 34: 1-43.

27. Toft I, Bønaa KH, Ingebretsen OC, Nordøy A, Birkeland KI, Jenssen T. Gender differences in the relationships between plasma plasminogen activator inhibitor- 1 activity and factors linked to the insulin resistance syndrome in essential hypertension. Arterioscler Thromb Vasc Biol 1997; 17: 553-559.

28. Siegert G, Bergman S, Jaross W. Influence on age, gender and lipoprotein metabolism parameter on the activity of the plasminogen activator inhibitor and the fibrinogen concentration. Fibrinolysis 1992; 6: 47-51.

29. Van Kesteren PJ, Kooistra T, Lansink M et al. The effects of sex steroids on plasma levels of marker proteins of endothelial cell functioning. Thromb Haemost 1998; 79: 1029-1033.

30. Jöreskog KG, Sörbom D. Lisrel 8 user's reference guide. Chicago: Scientific Software International, 1993.

31. Kluft C, Meijer P. Update 1996: blood collection and handling procedures for assessment of plasminogen activators and inhibitors (Leiden Fibrinolysis Workshop). Fibrinolysis \& Proteolysis 1996; 10 (suppl. 2): 171-179.

32. Walker ID. Blood collection and sample preparation: preanalytic variation. In: Jespersen J, Bertina RM, Haverkate F, eds. Laboratory techniques in thrombosis. A manual. Second revised edition of the ECAT assay procedures. Dordrecht, The Netherlands: Kluwer Academic Publishers, 1992: 21-28.

33. Ranby M, Sundell IB, Nilsson TK. Blood collection in strong acidic citrate anticoagulant used in a study of dietary influence on basal tPA activity. Thromb Haemost 1989; 62: 917-922.

34. Sobey WJ, Beer SF, Carrington CA et al. Sensitive and specific two-site immunoradiometric assays for human insulin, proinsulin, 65-66 split and 32-33 split proinsulins. Biochem J 1989; 260: 535-541.

35. Ruige JB, Dekker JM, Nijpels G et al. Hyperproinsulinaemia in impaired glucose tolerance is associated with a delayed insulin response to glucose. Diabetetologia 1999; 42: 177-180.

36. Friedewald WT, Levy RI, Frederickson DS. Estimation of the concentration of low density cholesterol in plasma, without use of the preparative ultracentrifuge. Clin Chem 1972; 18: 499-502.

37. Kluft C, Meijer P, Ersdal E, Rosen S. Tissue-type plasminogen activator (t-PA) activity. In: Jespersen J, Bertina RM, Haverkate $\mathrm{F}$ (eds) Laboratory techniques in thrombosis. A Manual. Second revised edition of the ECAT assay procedures. Dordrecht, The Netherlands: Kluwer Academic Publishers, 1992; 223-230.

38. Clauss A. Gerinnungsphysiologische Schnellmethode zur Bestimmung des Fibrinogens. Acta Haematol 1957; 17: 237-246.

39. Ranby M, Nguyen G, Scarabin PY, Samama M. Immunoreactivity of tissue plasminogen activator and of its inhibitor complexes. Biochemical and multicenter validation of a two site immunosorbent assay. Thromb Haemost 1989; 61: 409-414. 
40. Meijer P, Pollet DE, Wauters J, Kluft C. Specificity of antigen assays of plasminogen activator inhibitor in plasma: Innotest PAI-1 immunoassay evaluated. Clin Chem 1994; 40: 110-115.

41. McCullagh P, Nelder JA. Generalized linear models, 2nd edn. London: Chapman and Hall 1989; 61-70.

42. Fraser CG, Harris EK. Generation and application of data on biological variation in clinical chemistry. Crit Rev Clin Lab Sci 1989; 27: 409-437.

43. Cotlove E, Harris EK, Williams GZ. Biological and analytic components of variation in long-term studies of serum constituents in normal subjects. 3. Physiological and medical implications. Clin Chem 1970; 16: 1028-1032.

44. Bland JM, Altman DG. Measuring agreement in method comparison studies. Statistical Methods in Medical Research 1999; 8: 135-160.

45. Salomaa V, Rasi V, Stengard J et al. Intra- and interindividual variability of hemostatic factors and traditional cardiovascular risk factors in a three-year follow-up. Thromb Haemost 1998; 79: 969-974.

46. Chambless LE, McMahon RP, Brown SA, Patsch W, Heiss G, Shen YL . Short-term intraindividual variability in lipoprotein measurements: the Atherosclerosis Risk in Communities (ARIC) Study. Am J Epidemiol 1992; 136: 1069-1081.

47. Chambless LE, McMahon R. Wu K, Folsom A, Finch A, Shen YL. Short-term intraindividual variability in hemostatis factors. The ARIC Study. Ann Epidemiol 1992; 2: 723-733.

48. Wallnöfer AE, Van Griensven JMT, Schoemaker HC et al. Effect of isotretinoin on endogenous tissue-type plasminogen activator (t-PA) and plasminogen activator inhibitor 1 (PAI-1) in humans. Thromb Haemostas 1993; 70: 1005-1008.

49. Nguyen ND, Ghaddar H, Stinson V, Chambless LE, Wu KK. ARIC hemostasis study-IV. Intraindividual variability and reliability of hemostatic factors. The Atherosclerosis Risk in Communities (ARIC). Thromb Haemost 1995; 73: 256-260. 